\title{
Mechanical inefficiency of the thoracic cage in scoliosis
}

\author{
R S JONES, J D KENNEDY, F HASHAM, R OWEN, AND J F TAYLOR
}

From the Respiratory Unit, Alder Hey Children's Hospital and the Department of Child Health, University of Liverpool

ABSTRACT The mechanism of impairment of ventilatory function in idiopathic scoliosis has been studied in 23 children, all girls, and compared with 27 normal children and 24 normal young adult females. The vital capacity, $\mathrm{FEV}_{1}$, gas transfer factor, and the maximum static expiratory airway pressure were all significantly reduced. Total lung capacity and the maximum inspiratory pressure were lower than in the normal subjects, but the difference was not significant. Restriction of thoracic cage movement by a belt showed that the thorax in the children with scoliosis was as mobile as in the normal subjects. The results are explained in terms of the characteristic deformity in scoliosis which causes one hemi-thorax to become relatively smaller than the other. It is concluded that this causes an inherent mechanical inefficiency of ventilation which is likely to contribute to respiratory failure in these subjects.

The mechanisms of impairment of ventilatory function in idiopathic scoliosis are by no means clear. Standard pulmonary function tests in adults with idiopathic scoliosis show diminution of airway flow rates and reduction of lung volume compartments. ${ }^{1-6}$ The vital capacity (VC) is reduced, the total lung capacity (TLC) may be reduced, ${ }^{7-9}$ and gas transfer capacity has been reported low ${ }^{9}$ or high. ${ }^{10}$ Despite deformity of the thoracic cage and limitation of lung volume, the relaxation pressure curve is preserved in the child and young adult, but appears to become severely restricted in later life. ${ }^{11}$ Bergofsky et $a l^{3}$ reported an increase of elastic resistance which they regarded as mainly responsible for a large increase in the work of breathing.

No satisfactory explanation for these observations has been suggested. Denison et al ${ }^{10}$ asserted that the diminution in lung volume compartments could not be explained theoretically on the basis of lateral flexion or in terms of chest wall deformity, and suggested that elevation of the diaphragm caused by the associated kyphosis must be the explanation. This assumes that the kyphotic element of the deformity in scoliosis is comparable with forward flexion of the thoraco-lumbar spine in the normal subject, which of course is not true. Kyphosis in scoliosis is associated with compensatory curves so that usually the head and neck are not flexed with respect to the pelvis.

Address for reprint requests: Dr RS Jones, Respiratory Unit, Alder Hey Children's Hospital, Eaton Road, Liverpool L12 2AP.
Kyphosis may contribute to volume change in some $\stackrel{\circ}{\mathbb{D}}$ degree, but the essential deformities in scoliosis are $\overrightarrow{\vec{O}}$ rotation of the thoracic vertebrae about a vertical axis and the associated displacement of rib positions.

We approached the problem by examining the maximum static pressure-volume relationships in normal and scoliotic subjects. The relationship 으 between the maximum inspiratory and expiratory $\underset{x}{\mathscr{\chi}}$ pressures which can be exerted against a closed airway $\dot{0}$ at various lung volumes has been examined in normal subjects in considerable detail.12-16 Observations in $\stackrel{\text { }}{\text { 12 }}$ children with scoliosis have been few and the numbers observed small. ${ }^{11}{ }^{17}$ Cook et al, ${ }^{17}$ who studied eight 을 scoliotics, concluded that there was impairment of $>$ the maximum inspiratory pressure, but preservation of the normal expiratory pressure, a finding with which we disagree.

Limitation of chest movement in normal subjects $N$ by the application of a restricting belt to the thorax $\mathbb{\omega}_{\mathrm{N}}$ has been reported to produce effects on pulmonary 0 function similar to those observed in scoliotics. ${ }^{11} 0$ This technique has been applied to our normal and $\frac{\mathscr{D}}{\mathscr{D}}$ scoliotic subjects.

\section{Methods}

Twenty-three female children with idiopathic $\stackrel{\mathbb{D}}{\varrho}$ scoliosis who were attending the orthopaedic clinic were selected for study (table 1). Matched controls $ᄋ$ who were pupils from a neighbouring school formed 
Table 1 Normal subjects and scoliotic patients examined

\begin{tabular}{|c|c|c|c|c|c|c|}
\hline $\begin{array}{l}\text { Number of } \\
\text { normal subjects }\end{array}$ & $\begin{array}{l}\text { Mean age } \\
+ \text { range }(y r)\end{array}$ & Span $(\mathrm{cm})$ & $\begin{array}{l}\text { Number of } \\
\text { scoliotic patients }\end{array}$ & $\begin{array}{l}\text { Mean age } \\
+ \text { range }(y r)\end{array}$ & $\operatorname{Span}(\mathrm{cm})$ & $\begin{array}{l}\text { Cobb angle } \\
\text { Mean + range }\end{array}$ \\
\hline $\begin{array}{l}\text { Children } 27 \\
\text { Subsample } \\
\text { of children } 12\end{array}$ & $\begin{array}{l}14 \cdot 8 \\
(13-17) \\
14 \cdot 5 \\
(13-17)\end{array}$ & $\begin{array}{l}159 \cdot 5 \\
(\text { SD } 5 \cdot 71) \\
160 \cdot 2 \\
(\text { SD 6.78) }\end{array}$ & Children 23 & $\begin{array}{l}14 \\
(10-17)\end{array}$ & $\begin{array}{l}161 \cdot 1 \\
(S D 10 \cdot 59)\end{array}$ & $\begin{array}{l}48^{\circ} \\
\left(14-100^{\circ}\right)\end{array}$ \\
\hline
\end{tabular}

Table 2 Respiratory function in normal and scoliotic females

\begin{tabular}{|c|c|c|c|c|c|c|c|c|}
\hline $\begin{array}{l}\text { Number of } \\
\text { subjects }\end{array}$ & $T L C$ & $T L C^{\prime}$ & $\boldsymbol{R} V$ & $R V^{\prime}$ & $V C$ & $F E V_{1}$ & $T_{\mathrm{LCO}}$ & $T \mathrm{LCO} / F R C(s)$ \\
\hline Scoliotic 23 & $\begin{array}{c}3.53 \\
(0.81)\end{array}$ & $\begin{array}{c}3 \cdot 14 \\
(0 \cdot 23)\end{array}$ & $\begin{array}{c}1.08 \\
(0.29)\end{array}$ & $\begin{array}{c}1 \cdot 26 \\
(0 \cdot 31)\end{array}$ & $\begin{array}{c}2.45 \\
(0.63)\end{array}$ & $\begin{array}{c}2 \cdot 35 \\
(0 \cdot 60)\end{array}$ & $\begin{array}{l}15 \\
(3 \cdot 00)\end{array}$ & 8 \\
\hline Normal 12 & $\begin{array}{c}4.00 \\
(0.67)\end{array}$ & $\begin{array}{c}3.39 \\
(0.51)\end{array}$ & $\begin{array}{c}1 \cdot 01 \\
(0.38)\end{array}$ & $\begin{array}{c}1 \cdot 19 \\
(0 \cdot 33)\end{array}$ & $\begin{array}{c}2.99 \\
(0.52)\end{array}$ & $\begin{array}{c}2.83 \\
(0.28)\end{array}$ & $\begin{array}{l}19 \\
(3 \cdot 00)\end{array}$ & 9 \\
\hline $\mathrm{p}$ & $0.1>p>0.05$ & $\mathrm{p}>0 \cdot 1$ & $\mathrm{p}>0.1$ & $\mathrm{p}>0.1$ & $\mathrm{p}=0.02$ & $0.01>p>0.002$ & $0.002>p>0.001$ & $\mathrm{p}>0.01$ \\
\hline
\end{tabular}

All volumes are expressed in litres and transfer factor in $\mathrm{mlCO} / \mathrm{min} / \mathrm{mmHg}$.

TLC', RV': volumes corrected for pressure change and "leak".

(s) Specific transfer factor ${ }^{28}$.

Figures in parentheses $=1 \mathrm{SD}$.

Table 3 Volume and gas transfer changes produced by belt restriction

\begin{tabular}{|c|c|c|c|c|c|c|c|c|}
\hline \multirow{2}{*}{$\begin{array}{l}\text { Number of } \\
\text { subjects }\end{array}$} & \multicolumn{4}{|l|}{ No belt } & \multicolumn{4}{|l|}{ Belt } \\
\hline & $T L C$ & $R V$ & $V C$ & $T$ LCO & $T L C$ & $\boldsymbol{R} V$ & $V C$ & $T$ LCO \\
\hline Normal 12 & $\begin{array}{c}4.0 \\
(0.67)\end{array}$ & $\begin{array}{c}1.01 \\
(0.38)\end{array}$ & $\begin{array}{c}2.99 \\
(0.52)\end{array}$ & 19 & $\begin{array}{c}3.04 \\
(0.51)\end{array}$ & $\begin{array}{c}0.97 \\
(0.33)\end{array}$ & $\begin{array}{c}2 \cdot 07 \\
(0 \cdot 34)\end{array}$ & 14 \\
\hline Scoliotic 23 & $\begin{array}{c}3.53 \\
(0.81)\end{array}$ & $\begin{array}{c}1.08 \\
(0.29)\end{array}$ & $\begin{array}{c}2.45 \\
(0.63)\end{array}$ & 15 & $\begin{array}{c}2.54 \\
(0.52)\end{array}$ & $\begin{array}{c}1.08 \\
(0.29)\end{array}$ & $\begin{array}{c}1.46 \\
(0.41)\end{array}$ & - \\
\hline
\end{tabular}

Figures in brackets $=1 \mathrm{SD}$

Table 4 Airwav pressures in $\mathrm{cm}_{2} \mathrm{O}$ of normal and scoliotic subjects

\begin{tabular}{lllll}
\hline Number of subjects & $P I \max$ & $P E \max$ & $P E \max / P I \max$ \\
\hline Scoliotic children & 23 & $62.6(24)$ & $68 \cdot 1(23)$ & $1 \cdot 17^{*}$ \\
Normal children & 27 & $72 \cdot 8(25)$ & $97.8(21)$ & $1.48^{*}$ \\
p & & $p>0.05$ & $\mathrm{p}<0.001$ & $0.05>\mathrm{p}>0.02$ \\
Normal adults & 24 & $62.9(24)$ & $100.6(38)$ & $1.70^{*}$
\end{tabular}

* Means of values of PE max/PI max for each individual.

the 27 normal subjects studied. A subsample of 12 normal children had further lung function tests performed (table 2) and these, together with the scoliotic subjects, were examined using the belt restriction method (table 3). Measurements of airway pressure according to the methods described below were made on all these subjects (table 4). As there is a good deal of variation in the literature for results of static airway pressure measurements in normal subjects, we sought reassurance that our normal children were a reasonably representative group by comparing their results with results from 24 normal young female adults of 18-23 years (mean 20.3 years) drawn from the hospital staff using the same technique (table 4).

All the scoliotic subjects had thoracic curves and the angle was measured using the method of Cobb. ${ }^{18}$ No operative repair had been carried out before the study and no test was performed with the child in a brace. No patient was in cardiac failure and all children were asymptomatic at rest.

Lung volumes were measured using the helium dilution closed circuit technique. The transfer capacity was measured using the steady state carbon monoxide method. The maximum static airway pressures were measured using a modification of the technique of Cook et $a^{12}$ and Bird and Hyatt. ${ }^{19}$ The mouthpiece was a rigid rubber tube of $3 \mathrm{~cm}$ diameter in which was a hole of $1.25 \mathrm{~mm}$ in order to provide a leak, a technique used by the above authors to minimise artefacts. Various methods have been used to minimise leakage at the lips, but we found that the most satisfactory technique was to apply the lips around the rim of the rubber tube with fingers and thumb cupped in order to support the lips. The examination was made with the subject seated and a 
nose clip applied. The tube was connected to a Bell and Howell transducer calibrated before each test with a mercury manometer and measurements were recorded on a chart recorder.

The subject at first breathed to air via the tube and a three-way tap. In order to make a measurement of maximum expiratory pressure (PE max) she was asked to exhale to residual volume and inhale to total lung capacity (TLC), the amount inhaled being measured by a spirometer. At TLC the tap was turned to obstruct the airway. She was then asked to make a maximum expiratory effort, sustained for three seconds. The test was repeated until reproducible pressures were obtained. Maximum inspiratory pressures (PI max) were measured by asking the subject to breathe in to TLC and then out to RV, after which the airway was obstructed and a maximum inspiratory effort was performed.

A leather belt $8^{\prime \prime}$ deep and fastened at the back of the chest with buckles was used to restrict chest movement. A large sphygmomanometer cuff of the type used to measure blood pressure in the lower limbs was attached to its inner surface and served to adjust the level of pressure applied to the chest wall and to mould to the chest contours after the leather belt had been tightly applied. A second, small sphygmomanometer cuff also placed beneath the leather belt was employed to monitor the actual pressure achieved and was connected to a pressure transducer and chart recorder. The lung volume compartments and transfer capacity were measured in the scoliotics and 12 normal subjects (table 3 ).

Experiments were performed to measure the leak volume at varying pressures. The volumes at which pressures were measured were corrected using the calibration for leak volume and also to allow for the compression and expansion of gas in the lung in accordance with Boyle's law. These volume adjustments are recorded as TLC and RV in table 2. All volumes were corrected to BTPS. Statistical calculations were made using Student's two-sided $t$ test. Informed consent from patients and parents was obtained before the tests.

\section{Results}

The corrected and uncorrected TLCs in the scoliotic subjects were smaller, but not significantly so. The VC was significantly below normal, as also were the FEV $_{1}$ and the TLCo (table 2). The RV and the TLCo expressed per litre of lung volume did not differ significantly from normal.

\section{MAXIMUM AIRWAY PRESSURES}

The maximum mean airway pressure on expiration (PE max) was significantly lower in the scoliotics than in the normal subjects, $p<0.001$ (table 4). The maximum inspiratory pressure (PI max) was lower $\left(62.6 \mathrm{cmH}_{2} \mathrm{O}\right)$ in the scoliotics, but it was not significantly different from the normal $(72.8 \mathrm{~cm}$ $\mathrm{H}_{2} \mathrm{O}$ ). The mean pressures for PI max and PE max in the young adult female group approximated to those observed in the normal children.

The ratio PE max/PI max was significantly lower in the scoliotic group $(0.05>p>0.02)$. Although higher $(1 \cdot 70)$ in the adults, the difference between this value and the value for normal children $(1.48)$ is not significant. The ratio decreases with $\mathrm{VC}$ and tends to be less than unity in severe scoliosis (figure).

RESTRICTION OF VITAL CAPACITY BY BELT

The application of a restricting belt to the thoracic cage brought about a significant reduction of the TLC in normal subjects $(p<0.001)$ and scoliotics $(p<0.001)$ and of VC in normal subjects $(p<0.001)$ and scoliotics $(p<0.001)$ (table 3$)$. The RV did not change significantly in either group. The transfer capacity (TLCO) was significantly reduced $(p<0.001)$. As a result of these volume changes, the total lung capacity in the normal subjects when restricted becomes significantly greater than the corresponding value for the scoliotics $(0.02>p>0.01)$. On the other hand, the residual volume both in the normal and scoliotic subjects is not appreciably affected by belt restriction. Hence the already significant reduction of VC in the scoliotics becomes greater after belt restriction $(p<0.001)$. These results point to a mobile thorax in children which is smaller than normal and having a relative, but not actually, enlarged residual volume.

PE MAX, PI MAX, AND LUNG VOLUME

Although the airway was blocked off at TLC and RV, the effect on those volumes of "leak" (see methods) and of increase and decrease of gas pressure in the lung resulted in modified values, shown as TLC and RV (table 2). Hence, PE max and PI max were measured respectively at mean lung volumes of $11 \%$ below TLC and $17 \%$ above RV.

\section{Discussion}

Values for PI max and PE max for normal subjects reported in the literature have varied considerably. ${ }^{1314}$ Our values for older normal children are relatively low. We therefore examined a group of young adult female subjects. Their values are comparable with the results for our normal children, but again are lower than some reported in the literature. ${ }^{12} 20$ The reason for this is not clear. Technique is important, as has been pointed out by several authors, and for this reason we paid great attention to it. Volume corrections for gas compression and leak volume were of the same order as reported by other authors. 


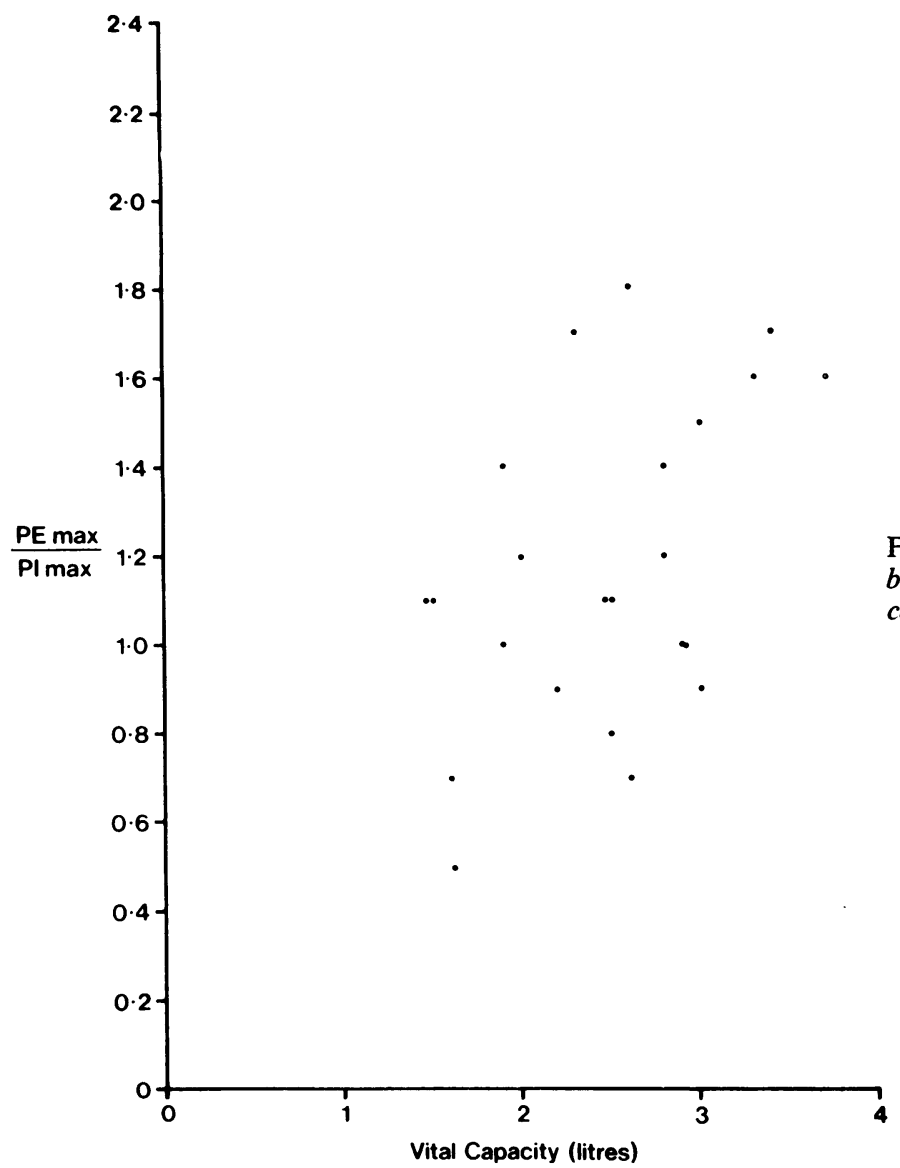

Figure There is a significant relationship between the ratio PE max/PI max and vital capacity in the scoliotic patients $(0.05>p>0.01)$
Cook et $a l^{17}$ made a further correction to PI max and PE max which attempted to allow for the smaller lung volume compartments observed in scoliosis, and therefore for the different positions on the pressure-volume curves at which measurements of PI max and PE max were supposedly made. For example, if our value for PE max is scaled in proportion to the ratio of the individual's TLC to the mean normal TLC, the mean PE max for the scoliotics becomes $71.3 \mathrm{cmH}_{2} \mathrm{O}$. If the value is scaled in proportion to the ratio of the individual's TLC to a matched control based on span, a rather higher mean value of $76.6 \mathrm{cmH}_{2} \mathrm{O}$ is obtained, but even this is significantly below the normal value $(p=0.05)$. The procedure is inadmissible, however, because each side of the chest in scoliosis is at a different point on the pressure-volume curve as discussed below.

\section{MOBILITY OF THE THORACIC CURVE}

It might be conjectured that the gross distortion in shape of the thoracic cage in scoliosis, and the associated decrease of VC, would be accompanied by rigidity of the bony framework, which would leave the diaphragm as the primary muscle for the maintenance of ventilation and gas exchange. If this had been the case in our subjects, the application of a belt to restrict primarily the thoracic cage movement, would not have decreased the VC appreciably in the scoliotics, but would have had a big effect in the normal subjects. The results do not support this view, since although the TLC was smaller ( 3.53 litres) in the scoliotics, its reduction was of the same order in the normal children, approximately one litre in each case. The RV in these two groups was almost the same, with and without belt restriction. We conclude that the thorax in our scoliotics is mobile, which agrees with the conclusions of other authors, ${ }^{11}$ but that the capacity to inflate the lungs is less in scoliosis.

MECHANICAL INEFFICIENCY OF THE THORACIC CAGE Reported abnormalities of pulmonary function in scoliosis have not been explained on a rational basis and in terms of the thoracic deformity and the 
mechanical consequences which arise from it. Volume change, and therefore ventilation, depends upon the mobility of the thoracic cage, the volume of each hemithorax, and the range over which each can be moved by the muscle power and the elastic force available. If it is assumed that the forces available are normal, a decrease of pressure suggests reduced mechanical efficiency.

From a functional point of view, the important primary deformity in scoliosis is lateral flexion plus rotation of the thoracic vertebrae about a vertical axis (primary rotation), with counter rotation of vertebrae above and below (secondary rotation) so that cervical and lumbar vertebrae are aligned normally. The further deformities of spine and attached ribs result in a decrease in the volume of one hemithorax with narrowing of intercostal spaces and a relative increase in the volume of the opposite hemithorax with widening of intercostal spaces. These effects on volume are supported by isotope scanning techniques which have confirmed that the volume of the lung on the concave side is reduced. ${ }^{21}{ }^{22}$ Within the constraints imposed by this relatively fixed rotational deformity the thoracic cage remains mobile.

The hemithorax and lung on the concave side are able to achieve an end-expiratory position near to normal, but cannot reach a normal end-inspiratory position. The opposite hemithorax and lung conversely achieve an end-inspiratory position approximating to normal, but cannot reach a normal endexpiratory position. In view of these considerations, effects on the static airway pressure-volume profiles for inspiration and expiration are to be expected. Thus, at a given level of overall lung volume, since the degree of inflation on the concave side is less, the contribution to PE will be smaller than on the relatively more inflated convex side. At TLC the concave side will contribute less to PE max. The convex side, even if the lung is fully inflated, will make no more than the normal contribution. Hence a subnormal value for PE max is to be expected, as was observed. Its value will relate to the degree of underinflation of the lung and relative expiratory position of the thoracic cage on the concave side. The effect on pressure will apply throughout the pressure-volume profile and hence in the range of tidal breathing. These consequences of asymmetry must be considerable when the overall volume of the lung is reduced, as is reported in most series. Lung volume components were smaller, but only VC significantly so, in our relatively mild group.

Since the convex side may not achieve a normal end-expiratory position, the contributions of the intercostal muscles and hemi-diaphragm to PI max could be reduced. Our value for PI max was smaller, although not significantly so, but might well have been in a more severely affected group of subjects. As a result of these pressure changes, the ratio PE $\max / \mathrm{PI} \max$ is reduced significantly in scoliosis and decreases in proportion to the decrease in VC (figure).

There is therefore an inherent decrease of mechanical efficiency of the thoracic cage in scoliosis with of a thoracic curve. This will operate also in paralytic $\vec{\circ}$ scoliosis and contribute to the decrease of ventilatory capacity caused by muscle weakness.

This work was supported by a grant from the Intensive Care Fund, Alder Hey Children's Hospital.

\section{References}

1 Chapman EM, Dill DB, Graybiel A. The decrease in functional capacity of the lungs and heart resulting from deformities of the chest: pulmonocardiac failure. Medicine (Baltimore) 1939; 18:167-202.

2 Iticovici HW, Lyons HA. Ventilatory and lung volume determinations in patients with chest $ळ$ deformities. Am J Med Sci 1956; 232:265-75.

3 Bergofsky EH, Turino GM, Fishman AP. Cardiorespiratory failure in kypho-scoliosis. Medicine (Baltimore) 1959; 38:263-317.

4 Gazioglu K, Goldstein LA, Femi-Pearse D, Yu PN. Pulmonary function in idiopathic scoliosis. Comparative evaluation before and after orthopaedic correction. J Bone Joint Surg $(A)$ 1968; 50:1391-9.

5 Lindh M, Bjure J. Lung volumes in scoliosis before and after correction by the Harrington instrumentation method. Acta Orthop Scand 1975; 46:934-48.

6 Prime FJ. A review of lung function in scoliotic subjects. In: Zorab PA, ed. Scoliosis. Proceedings of 은 the Fifth Symposium. London: Academic Press, 1977.

7 Godfrey S. Respiratory and cardiovascular con- sequences of scoliosis. Respiration 1970; Suppl 27: 67-70.

8 Shannon DC, Riseborough EJ, Valenca LM, Kazemi Homayoun. The distribution of abnormal lung function in kyphoscoliosis. J Bone Joint Surg $(A)$ $1970 ; 52: 131-44$.

9 Weber B, Smith JP, Briscoe WA, Friedman SA, 을 King TKC. Pulmonary function in asymptomatic $N$ adolescents with idiopathic scoliosis. Am Rev Respir or Dis 1975; 111:389-97.

10 Denison DM, Bellamy D, Pierce RJ. Some observations on lung function in scoliosis. In: Zorab PA, Siegler D, eds. Scoliosis. Proceedings of the Sixth Symposium. London: Academic Press, 1979.

11 Caro CG, Dubois AB. Pulmonary function in kyphoscoliosis. Thorax 1961; 16:282-90.

12 Cook CD, Mead J, Orzalesi MM. Static volume- T pressure characteristics of the respiratory system during maximal efforts. J Appl Physiol 1964; 19: 1016-23.

13 Ringqvist $T$. The ventilatory capacity in healthy subjects: an analysis of causal factors with special reference to the respiratory forces. Scand J Clin Lab Invest 1966; 18: Suppl 88. 
14 Black LF, Hyatt RE. Maximal respiratory pressures: normal values and relationship to age and sex. $\mathrm{Am}$ Rev Respir Dis 1969; 99:696-702.

15 De Troyer A, Yernault JC. Inspiratory muscle force in normal subjects and patients with interstitial lung disease. Thorax 1980; 35:92-100.

16 Rahn H, Otis AB, Chadwick LE, Fenn WO. The pressure-volume diagram of the thorax and lung. Am J Physiol 1946; 146:161-78.

17 Cook CD, Barrie H, DeForest SA, Helliesen PJ. Pulmonary physiology in children. III. Lung volumes: mechanics of respiration-respiratory musclestrength in scoliosis. Paediatrics 1960; 25:766.

18 Cobb SR. Instructional Course Lecture. American Academy of Orthopaedic Surgeons 1948; 5:261.
19 Byrd RB, Hyatt RE. Maximal respiratory pressures in chronic obstructive lung disease. Am Rev Respir Dis 1968; 98:848-56.

20 Rochester DF, Braun NMT, Arora NS. Respiratory muscle strength in chronic obstructive pulmonary disease. Am Rev Respir Dis 1979; 119:151-4.

21 Dollery CT, Gillam PMS, Hugh-Jones P, Zorab PA. Regional lung function in kyphoscoliosis. Thorax $1965 ; 20: 175-81$.

22 Littler WA, Brown IK, Roaf R. Regional lung function in scoliosis. Thorax 1972; 27:420-8.

23 Weng TR, Levison H. Standards of pulmonary function in children. Am Rev Respir Dis 1969; 99:879-94. 